\title{
Ovine Placental and Fetal Arginine Metabolism at Normal and Increased Maternal Plasma Arginine Concentrations
}

\author{
PATTI J. THUREEN, KAREN A. BARON, PAUL V. FENNESSEY, AND WILLIAM W. HAY, JR. \\ Perinatal Research Center, Department of Pediatrics, University of Colorado Health Sciences Center, \\ Denver, Colorado, 80262, U.S.A.
}

\begin{abstract}
ABST stimulating insulin secretion and as a precursor for both polyamine synthesis and nitric oxide production. To determine whether increased maternal plasma A concentrations can enhance delivery of A to the fetus, uterine, umbilical, and net uteroplacental (UP) A uptake rates were measured in 12 pregnant ewes at $129.6 \pm 0.4 \mathrm{~d}$ gestation (mean $\pm \mathrm{SEM}$ ) during normal and after $3 \mathrm{~h}$ of increased maternal plasma A concentrations. With a 2.7-fold increase in maternal plasma A concentrations ( $p$ $<0.001)$, there were significant increases in uterine A uptake $(13.8 \pm 1.0$ to $41.3 \pm 7.7 \mu \mathrm{mol} / \mathrm{min}, p<0.005)$, umbilical A uptake $\left(3.3 \pm 0.5\right.$ to $5.2 \pm 0.8 \mu \mathrm{mol} \cdot \mathrm{min}^{-1} \cdot \mathrm{kg}^{-1}$ fetus, $p<$ $0.005)$, UP A uptake $(17.8 \pm 6.2$ to $89.2 \pm 20.3$ $\mu \mathrm{mol} \cdot \mathrm{min}^{-1} \cdot \mathrm{kg}^{-1}$ placenta, $\left.p<0.01\right)$, fetal arterial A concen-
\end{abstract}

tration $(98.7 \pm 6.3$ to $137.1 \pm 9.9 \mu \mathrm{M}, p<0.001)$, maternal A disposal rate $(143.7 \pm 9.4$ to $217.0 \pm 6.7 \mu \mathrm{mol} / \mathrm{min}, p<0.001)$, fetal A disposal rate $\left(7.9 \pm 0.8\right.$ to $9.9 \pm 1.1 \mu \mathrm{mol} \cdot \mathrm{min}^{-1} \cdot \mathrm{kg}^{-1}$, $p<0.05)$, fetal A oxidation rate $(1.31 \pm 0.24$ to $1.84 \pm 0.36$ $\left.\mu \mathrm{mol} \cdot \mathrm{min}^{-1} \mathrm{~kg}^{-1}, p<0.05\right)$, and plasma insulin concentration in both fetus $(16 \pm 2$ to $20 \pm 2 \mu \mathrm{U} / \mathrm{mL}, p<0.001)$ and mother ( $24 \pm 3$ to $32 \pm 4 \mu \mathrm{U} / \mathrm{mL}, p<0.001)$. Thus, increased maternal plasma A concentration increases maternal, UP, and fetal A net uptake, and increases insulin secretion in mother and fetus. The 4.2-fold larger increase in UP than net fetal A uptake could represent preferential UP A metabolism relative to fetal A metabolism, relatively limited placental-fetal A transport capacity compared with uterine A uptake capacity, or both; responsible mechanisms remain unknown. (Pediatr Res 51: 464-471, 2002)
Arginine is a conditionally indispensable amino acid in the mammalian fetus and neonate $(1,2)$, and maintenance of fetal arginine supply and plasma concentrations are important for optimal fetal growth. The mechanisms by which arginine promotes fetal growth, however, are multifaceted and have not been adequately investigated. Arginine is an insulin secretagogue in ovine and human fetuses (3-7) and in human newborns $(8-10)$; thus the role of arginine in fetal growth may include an insulin-mediated anabolic effect. In addition, arginine could stimulate growth as a precursor for polyamine synthesis (11) and nitric oxide production (12-14).

In contrast, arginine deficiency has been shown to induce growth restriction in experimental animals $(15,16)$. A potential therapy for fetal growth restriction, therefore, could include maternal plasma arginine supplementation in an attempt to increase fetal arginine supply. It is not known, however, whether increasing maternal plasma arginine concentration could increase net fetal arginine uptake, fetal plasma arginine

Received March 7, 2001; accepted June 19, 2001.

Correspondence and reprint requests: Patti J. Thureen, M.D., Section of Neonatology, B-195, University of Colorado Health Sciences Center, 4200 East 9th Avenue, Denver, CO 80262, U.S.A.; e-mail: patti.thureen@uchsc.edu

Supported by National Institutes of Health grants HD01061, HD20761, and HD28794. concentration, or fetal insulin concentration. In addition, the characteristics of placental arginine uptake, metabolism, and transport to the fetus have not been determined. Therefore, this study was designed to determine how maternal arginine supplementation affects maternal, uteroplacental, and fetal arginine net uptake rates, setting the stage for future investigations of the role of arginine in regulating placental and fetal arginine metabolism and growth.

\section{METHODS}

\section{Animal Care and Surgical Procedure}

Studies were performed in 12 late-gestation ColumbiaRambouillet pregnant sheep obtained from a commercial breeder (Nebeker Ranch, Santa Monica, CA, U.S.A.). Pregnancies were time-dated, and all were known singleton pregnancies. After a 24-h fast, each ewe was prepared for surgery with i.v. pentobarbital sodium sedation $(5 \mathrm{mg} / \mathrm{kg}$ initial dose followed by additional small bolus infusions as needed) and lumbar intrathecal tetracaine hydrochloride anesthesia $(6 \mathrm{mg}$ in hypertonic glucose). Ampicillin (500 mg) and gentamicin (80 $\mathrm{mg}$ ) were given intramuscularly preoperatively. At surgery, maternal polyvinyl catheters were placed via a groin incision 
into the femoral artery for blood sampling and into the femoral vein for infusions. After laparotomy and hysterotomy, catheters were placed in each of the two uterine veins draining the uterine horns, and fetal catheters were placed into the abdominal aorta via hindlimb arteries for blood sampling and into the femoral veins via hindlimb veins for infusions. An umbilical venous catheter was also placed with the tip advanced into the common umbilical vein. Ampicillin (500 mg) was injected into the amniotic fluid just before closing the uterine incision. All catheters were tunneled s.c. through a maternal skin incision and maintained within a plastic pouch secured to the ewe's flank. Catheters were flushed every other day with heparinized saline (150 U heparin $/ \mathrm{mL}$ of $0.9 \% \mathrm{wt} / \mathrm{vol} \mathrm{NaCl}$ in water). Animals were allowed to recover for 5-7 d before study. All animals were standing by $6 \mathrm{~h}$ after surgery, and were allowed ad libitum access to alfalfa pellets, water, and a mineral block. The ewes were maintained in a temperature-controlled environment $\left(18 \pm 2{ }^{\circ} \mathrm{C}\right)$ and were exposed to a cycle of $18 \mathrm{~h}$ of variable light followed by $6 \mathrm{~h}$ of darkness every $24 \mathrm{~h}$. All studies were approved by the University of Colorado Health Sciences Center Animal Care and Use Committee. Studies were performed at the UCHSC Perinatal Research Facility, which is accredited by the National Institutes of Health, the U.S. Department of Agriculture, and the American Association for the Accreditation of Laboratory Animal Care.

\section{Experimental Design}

Each study was performed 5 to $7 \mathrm{~d}$ after surgery. Each animal was studied only once. The study was begun approximately $4 \mathrm{~h}$ after the last access to feed. Each ewe was restrained in an animal cart next to a similarly housed sheep. The animal was allowed free access to water. Figure 1 depicts overall study design. There were two discrete 3 -h experimental periods: period 1 and period 2, denoting study during normal and elevated maternal arginine concentrations, respectively. In a preliminary study, a single pregnant ewe was infused with arginine hydrochloride at four different infusate concentrations to determine a dose that would approximately triple the maternal arginine concentration. From this preliminary study, in period 2 (approximately $220 \mathrm{~min}$ into the study), the pregnant

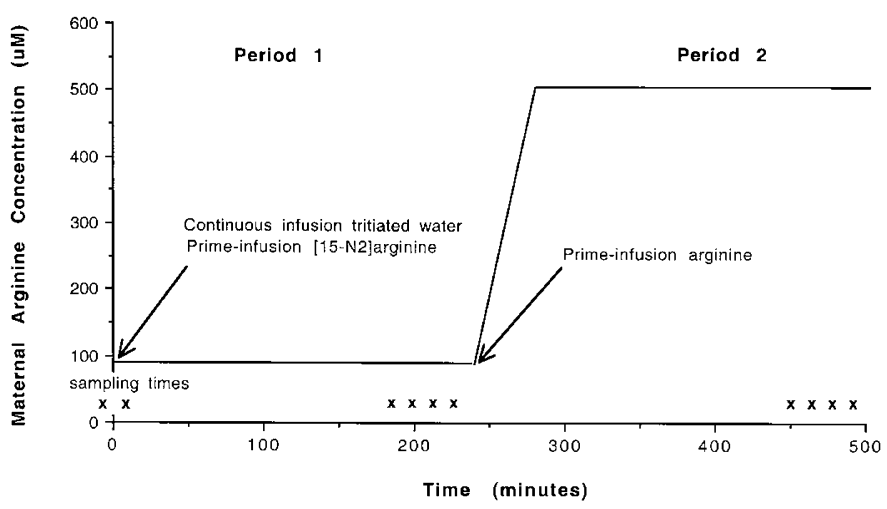

Figure 1. Experimental protocol. Period 1 indicates the study conducted with no maternal arginine supplementation, and period 2 is the study segment after the mother has received a primed infusion of arginine sufficient to raise the maternal plasma arginine concentration approximately 3 -fold. ewe was infused with arginine [the first animal was infused with L-arginine hydrochloride (mol wt, 210.7; ICN Biochemicals, Cleveland, OH, U.S.A.) and the subsequent seven animals were infused with L-arginine free base (mol wt, 174.2; ICN Biochemicals)]. For both arginine forms, the infusate was prepared by diluting the arginine in $0.9 \% \mathrm{wt} / \mathrm{vol} \mathrm{NaCl}$ in water and then adding acetic acid $(0.1 \mathrm{~N})$ to achieve a $\mathrm{pH}$ of $6.0-8.0$. In all animals, the maternal arginine infusion rate for period 2 was $13.3 \mathrm{mg} / \mathrm{min}$ after a prime of $996 \mathrm{mg}$.

At time 0 , a bolus of ${ }^{15} \mathrm{~N}_{2}$-arginine (Cambridge Isotope Laboratories, Woburn, MA, U.S.A.), $1.85 \mathrm{mg}$ in normal saline, was administered during $5 \mathrm{~min}$ into the maternal venous circulation via the femoral vein, followed by a constant infusion of ${ }^{15} \mathrm{~N}_{2}$-arginine to determine maternal arginine disposal rate and uterine arginine clearance. During period 1, there was a constant infusion of ${ }^{15} \mathrm{~N}_{2}$-arginine at $1.38 \mathrm{mg} / \mathrm{min}$. During period 2, the constant infusion of ${ }^{15} \mathrm{~N}_{2}$-arginine was increased to $1.68 \mathrm{mg} / \mathrm{min}$, an estimated infusion rate designed to keep the maternal plasma enrichments approximately the same during period 1 (no maternal arginine infusion) and period 2 (maternal arginine infusion). Concurrently, $\left[\mathrm{U}-{ }^{14} \mathrm{C}\right]$ arginine was infused at $10.8 \mu \mathrm{Ci} / \mathrm{h}$ into the fetus to determine fetal arginine disposal and oxidation rates and ${ }^{3} \mathrm{H}_{2} \mathrm{O}$ was infused at $16.8 \mu \mathrm{Ci} / \mathrm{h}$ into the fetus to measure umbilical and uterine blood flows. These tracers were infused throughout the study via a fetal hindlimb vein after a priming dose equal to $80 \mathrm{~min}$ of infusion given during $5 \mathrm{~min}$.

Samples were drawn at time 0 (in duplicate), at 180, 190, 200, and $210 \mathrm{~min}$ (end of period 1) and at 400, 410, 420, and $430 \mathrm{~min}$ (end of period 2). Blood was sampled simultaneously from the uterine venous, maternal arterial, fetal arterial, and umbilical venous catheters. Samples were analyzed for hematocrit, blood oxygen content and oxygen saturation, plasma concentrations of glucose, lactate, arginine, insulin, $\left[\mathrm{U}-{ }^{14} \mathrm{C}\right]$ arginine, ${ }^{3} \mathrm{H}_{2} \mathrm{O}$, and enrichment of ${ }^{15} \mathrm{~N}_{2}$-arginine. Because of significant sampling volume, the total volume of blood sampled for analysis during each set of samples was replaced with an equivalent volume of maternal donor blood at the end of the first sampling period to maintain $\mathrm{Hb}$ concentration and blood volume throughout the study.

At the end of the study, infusate solutions were retained for confirmation of isotopic purity, stable isotopic enrichment, and radioisotope specific activity. After completion of studies, lethal doses of euthanasia solution were injected into the mother (12 mL i.v.) and fetus ( $2 \mathrm{~mL}$ intracardiac; Sleepaway, sodium pentobarbital in $10 \%$ alcohol, Fort Dodge Laboratories, Fort Dodge, IA, U.S.A.). At autopsy, the fetus, uterus, uterine membranes, and cotyledons were removed and weighed separately. Fetal study weight was extrapolated from gestational age at study and weight and gestational age at autopsy according to ovine in utero growth curves in our laboratory for Columbia-Rambouillet sheep.

\section{Blood Sampling Technique and Analytical Methods}

Fetal arterial blood samples for measurement of glucose and insulin concentrations $(1.3 \mathrm{~mL})$ were collected in plastic syringes lined with EDTA. Blood $(0.3 \mathrm{~mL})$ was collected in 
heparin-coated capillary syringes for determination of $\mathrm{Hb}$ concentration and oxygen saturation. Plasma was separated within 5 min of sampling in a refrigerated centrifuge. Samples were processed immediately for plasma glucose and lactate (YSI glucose and lactate analyzer, Yellow Springs Instruments, Yellow Springs, OH, U.S.A.) and blood oxygen content (OSM III Hemoximeter, Radiometer, Copenhagen, Denmark, calibrated for fetal ovine $\mathrm{Hb}$ ). Plasma for insulin concentration was frozen immediately and stored at $-70^{\circ} \mathrm{C}$ until analysis; concentrations were determined with an RIA kit (Linco Research, St. Louis, MO, U.S.A.) using ovine standards provided by Eli Lilly (Indianapolis, IN, U.S.A.). For determination of ${ }^{3} \mathrm{H}_{2} \mathrm{O}, 0.1-\mathrm{mL}$ plasma samples were solubilized in $1.0 \mathrm{~mL}$ of Soluene-350 (quaternary ammonium hydroxide in toluene, Packard Instrument Co., Meriden, CT, U.S.A.) and then mixed with $15 \mathrm{~mL}$ of Hionic Fluor (Packard). The ${ }^{14} \mathrm{C}$ and ${ }^{3} \mathrm{H}$ radioactivities were measured in a Packard Tri-Carb $460 \mathrm{C}$ liquid scintillation counter. Samples $(1.6 \mathrm{~mL})$ for determination of plasma arginine concentration and stable isotope enrichment were collected in EDTA-coated syringes, centrifuged, and stored at $-70^{\circ} \mathrm{C}$ until analysis.

Plasma ${ }^{15} \mathrm{~N}_{2}$-arginine enrichment and plasma arginine concentration were determined using the following method. Fifty nanomoles of $\left[\mathrm{U}_{-}{ }^{13} \mathrm{C}\right]$ arginine was added to $250-\mu \mathrm{L}$ aliquots of plasma as an internal standard. An amino acid-rich fraction was isolated using a Dowex 50 hydrogen form, 100-200 mesh column (Bio-Rad, Richmond, CA, U.S.A.). The eluates were vacuum dried and derivatized using trifluoroacetic anhydride, and the derivatives were analyzed using gas chromatographymass spectrometry. A DB1 column $(15 \mathrm{~m} \times 0.25 \mathrm{~mm} \times 25$ $\mu \mathrm{m}$ film thickness, J\&W, Inc., Folsom, CA, U.S.A.) was interfaced to an HP 9570 MSD (Hewlett-Packard, Inc., Palo Alto, CA, U.S.A.). Ions were monitored at $\mathrm{m} / \mathrm{z} 375,376,377$, and 381. Enrichments were calculated from ion ratios of $\mathrm{m} / \mathrm{z}$ 375/377. Plasma arginine concentrations were calculated by isotope dilution technique referenced to a standard curve.

\section{Calculations}

Plasma and blood flows and net fluxes of arginine, glucose, and oxygen. Umbilical $\left(\mathrm{PF}_{\mathrm{umb}}\right)$ and uterine $\left(\mathrm{PF}_{\mathrm{ut}}\right)$ plasma flows $(\mathrm{mL} / \mathrm{min})$ were calculated from ${ }^{3} \mathrm{H}_{2} \mathrm{O}$ samples using the steady-state transplacental diffusion method with tritiated water as the flow indicator (17). Umbilical $\left(\mathrm{BF}_{\mathrm{umb}}\right)$ and uterine $\left(\mathrm{BF}_{\mathrm{ut}}\right)$ blood flows were calculated as follows (18):

$$
\begin{aligned}
& \mathrm{BF}_{\mathrm{umb}}=\left(\mathrm{PF}_{\mathrm{umb}}\right) /(1-\text { fractional fetal hematocrit }) \\
& \mathrm{BF}_{\mathrm{ut}}=\left(\mathrm{PF}_{\mathrm{ut}}\right) /(1-\text { fractional maternal hematocrit })
\end{aligned}
$$

In general, arteriovenous amino acid concentration differences across the uterine circulation are relatively small, limiting the accuracy of net amino acid uptake calculations. Amino acid uptake by tissue is limited primarily to plasma amino acids (as opposed to plasma plus red blood cell amino acids), and plasma concentration differences across organs such as the placenta are approximately $50 \%$ greater than for whole blood. Thus, uterine and umbilical amino acid uptakes are more accurately determined by measuring plasma uptakes (18).
Therefore, arginine net uptake rates $(\mu \mathrm{mol} / \mathrm{min})$ were calculated as follows:

$$
\begin{gathered}
\text { Net Umb (fetal) A uptake rate }=\left(\mathrm{PF}_{\mathrm{umb}}\right) \times[\Delta \mathrm{A}]_{\mathrm{v}-\mathrm{a}} \\
\text { Net Ut A uptake rate }=\left(\mathrm{PF}_{\mathrm{ut}}\right) \times[\Delta \mathrm{A}]_{\mathrm{A}-\mathrm{V}}
\end{gathered}
$$

where $[\Delta \mathrm{A}]$ is the arginine concentration difference in across the fetal venous (v) and arterial (a) and maternal arterial (A) and venous (V) circulations, respectively. Net glucose uptake rates were calculated in the same manner, but oxygen uptake was determined using blood flow rather than plasma flow. Net uteroplacental arginine uptake rate was calculated as net uterine - net umbilical arginine uptake rate.

Maternal and fetal plasma arginine disposal rates, fetal arginine oxidation rate, and uterine arginine clearance rate. Maternal plasma arginine disposal rate ( $\left.\mathrm{DR}_{\text {arg,mat }}\right)$ was calculated as follows:

$$
\mathrm{DR}_{\text {arg,mat }}=\operatorname{Inf}_{\text {arg.mat }} \times\left[\left(\mathrm{MPE}_{\text {Inf }} / \mathrm{MPE}_{\mathrm{A}}\right)-1\right]
$$

where Inf ${ }_{\text {arg,mat }}$ is the rate of infusion of ${ }^{15} \mathrm{~N}_{2}$-arginine into the mother, $\mathrm{MPE}_{\text {Inf }}$ is the mol percent excess or ${ }^{15} \mathrm{~N}_{2}$-arginine enrichment of the infusate, and $\mathrm{MPE}_{\mathrm{A}}$ is the percent enrichment of ${ }^{15} \mathrm{~N}_{2}$-arginine in maternal arterial plasma. Fetal plasma arginine disposal rate $\left(\mathrm{DR}_{\mathrm{arg}, \mathrm{fet}}\right)$ was calculated as follows:

$$
\mathrm{DR}_{\text {arg,fet }}=\left(\mathrm{Inf}_{\text {arg,fet }}\right) / \mathrm{SA}_{\text {arg }}
$$

where $\operatorname{Inf}_{\text {arg,fet }}$ is the rate of infusion of $\left[\mathrm{U}_{-}{ }^{14} \mathrm{C}\right]$ arginine into the fetus and $\mathrm{SA}_{\text {arg }}$ is the steady-state fetal arterial arginine specific activity (in dpm/ $\mu \mathrm{mol}$ ). Fetal arginine oxidation rate was calculated as net fetal ${ }^{4} \mathrm{CO}_{2}$ excretion rate (equal to the product of umbilical blood flow and the concentration difference of ${ }^{14} \mathrm{CO}_{2}$ between umbilical arterial and venous blood) divided by the fetal plasma ${ }^{14} \mathrm{C}$-arginine specific activity.

Uterine arginine clearance rate was calculated as the net uterine arginine uptake rate divided by the maternal arterial plasma arginine concentration. Uteroplacental arginine clearance was calculated as net uteroplacental arginine uptake (consumption) rate divided by the maternal plasma arginine concentration. Maternal and fetal plasma arginine clearance rates were calculated as maternal or fetal plasma arginine disposal rate divided by maternal or fetal plasma arginine concentration, respectively.

\section{Data Analysis}

Results are expressed as mean \pm SEM. Differences between basal and study periods were assessed by two-tailed paired $t$ test.

\section{RESULTS}

Fetal age and study weights for 12 experimental animals are shown in Table 1. Estimated fetal weight at study was calculated from autopsy weight. There were no differences in uterine and umbilical plasma and blood flows between periods 1 and 2 (Table 2). Although there were some small but significant differences in plasma glucose and lactate concentrations and oxygen saturation and content values between periods (Table 
Table 1. Fetal age and study weights

$\begin{array}{lc}\text { Pregnant Columbia-Rambouillet sheep } & n=12 \\ \text { Maternal weight (kg) } & 43.0 \pm 1.6 \\ \text { Fetal gestational age at study (d) } & 129.6 \pm 0.4 \\ \text { Fetal weight at study (g) } & 2766 \pm 88 \\ \text { Placental weight at autopsy (g) } & 296 \pm 18 \\ \text { Combined weight of the uterus }+ \text { placenta }+ \text { fetus }(\mathrm{g}) & 422 \pm 20\end{array}$

3 ), this did not result in any significant differences in net uterine or umbilical uptake rates of glucose, lactate, or oxygen (Table 4). Despite blood transfusion during the study, the maternal and fetal arterial hematocrits were significantly lower during period 2 (presumably because of blood sampling), but only by $3.5 \%$ and $4.6 \%$, respectively (Table 3 ), not an amount that would be of physiologic significance.

Mean plasma arginine concentration was significantly increased in both fetal and maternal vessels in period 2 versus period 1 , increasing by $170 \%$ in maternal vessels and $40 \%$ in fetal vessels (Fig. 2, top). The large variability among animals in arginine concentrations in the maternal vessels in period 2 reflects that the same arginine prime and infusion doses were given to all animals and were not adjusted for maternal weight. In a single animal, plasma arginine concentrations were drawn every $5 \mathrm{~min}$, and maternal steady-state was reached at approximately $20 \mathrm{~min}$ after the arginine prime-infusion was started. Mean fetal and maternal arginine enrichments also are shown in Figure 2, bottom. As noted in "Methods," during period 2, the rate of the ${ }^{15} \mathrm{~N}_{2}$-arginine constant infusion was increased to keep the maternal plasma enrichments approximately the same during periods 1 and 2. This was attained in the maternal vessels, although fetal arginine enrichments increased significantly during period 2 .

Net uterine arginine uptake rate was significantly increased (3-fold) with maternal arginine supplementation, as was net umbilical (fetal) arginine uptake rate (56\% increase; Table 5). Uterine arginine clearance rate did not change from period 1 to period 2 (Table 5). Net uteroplacental arginine uptake rate increased 4-fold in period 2 compared with period 1. Uteroplacental arginine clearance tended to decrease, but the change was not significant (Table 5).

Both maternal $(+51 \%)$ and fetal $(+26 \%)$ arginine disposal rates were significantly increased during maternal arginine infusion in period 2, as was the fetal arginine oxidation rate ( $+41 \%$; Table 5). Maternal arginine clearance rate decreased by $37 \%$ during period 2 , whereas there was no change in fetal plasma arginine clearance rate (Table 5).

Table 2. Plasma flows during study period 1 (normal maternal plasma arginine concentration) and study period 2 (elevated maternal plasma arginine concentration)*

\begin{tabular}{lcc}
\hline \multicolumn{1}{c}{ Plasma flows } & Period 1 & Period 2 \\
\hline Uterine $(\mathrm{mL} / \mathrm{min})$ & $1299 \pm 119$ & $1331 \pm 140$ \\
Uterine $/ \mathrm{kg} \mathrm{fetus}\left(\mathrm{mL} \cdot \mathrm{kg}^{-1} \cdot \mathrm{min}^{-1}\right)$ & $472 \pm 40$ & $479 \pm 48$ \\
Umbilical $(\mathrm{mL} / \mathrm{min})$ & $488 \pm 38$ & $497 \pm 41$ \\
Umbilical $/ \mathrm{kg} \mathrm{fetus}\left(\mathrm{mL} \cdot \mathrm{kg}^{-1} \cdot \mathrm{min}^{-1}\right)$ & $173 \pm 10$ & $178 \pm 11$ \\
\hline
\end{tabular}

* No significant differences in plasma flows between periods 1 and 2 as determined by paired, two-tailed $t$ test.
Insulin concentrations increased significantly in period 2 in both the mother ( $24 \pm 3$ to $32 \pm 4 \mu \mathrm{U} / \mathrm{mL}, p<0.001$ ) and the fetus (16 \pm 2 to $20 \pm 2 \mu \mathrm{U} / \mathrm{mL}, p<0.001$ ).

In two animals, plasma amino acid profiles were measured. Ornithine concentration increased 2.7-fold in the maternal plasma and 1.9-fold in fetal plasma at elevated maternal plasma arginine concentration compared with baseline, but citrulline concentration did not change in either maternal or fetal plasma.

\section{DISCUSSION}

The results of the present study show that an increase in maternal plasma arginine concentration produced a large variety of changes in maternal, uteroplacental, and fetal metabolism. The increased arginine concentration led to increased uterine, uteroplacental, and fetal net arginine uptake rates. The increase in uteroplacental arginine consumption was relatively greater than the increase in net placental-to-fetal arginine transfer, indicating nonproportionality and thus different mechanisms of regulation between placental metabolism and placental transport of arginine. The increased maternal and fetal arginine concentrations also were associated with increased fetal and maternal insulin concentrations and fetal and maternal arginine disposal (plus fetal oxidation) rates. The greater fractional increase in fetal arginine oxidation rate $(+41 \%)$ compared with fetal plasma arginine disposal rate $(+26 \%)$ indicates that increased arginine supply to the fetus is preferentially oxidized, substituting therefore for oxidation of other carbon substrates such as glucose, lactate, and other amino acids, inasmuch as the rate of fetal oxygen consumption did not change. Fetal oxygen saturation values also were lower, perhaps representing increased substrate oxidation rates because of increased insulin action, although there was no measurable change in fetal oxygen consumption rate. The increased maternal disposal rate of arginine was not proportional to the increase in maternal plasma arginine concentration in contrast to the fetus, in which arginine clearance did not change. In the mother, therefore, the increased supply and concentration of arginine either decreased arginine production or arginine disposal already was close to maximal in the basal state at normal physiologic concentrations. In the fetus, the increased supply and concentration of arginine in period 2 was proportional to the increase in disposal rate (no change in clearance), indicating that there was no limitation of arginine disposal based on plasma concentration. However, the fractional increase in placental arginine supply to the fetus $(+56 \%)$ was greater than the fractional increase in disposal rate $(+26 \%)$, indicating that fetal arginine production rate was decreased by the increased arginine supply. The increased uterine arginine uptake rate was proportional to the increase in maternal arterial plasma arginine concentration, but the fractional increase in uteroplacental arginine utilization rate exceeded the increase in maternal arginine concentration, although the latter change was not quite sufficient to represent an increase in uteroplacental clearance rate. Importantly, therefore, a simple, physiologic increase in maternal plasma arginine concentration produces several sig- 
Table 3. Glucose and lactate concentrations, oxygen saturation, and oxygen content during study period 1 (normal maternal plasma arginine concentration) and study period 2 (elevated maternal plasma arginine concentration)

\begin{tabular}{|c|c|c|c|c|}
\hline & $\begin{array}{c}\text { Maternal } \\
\text { femoral artery } \\
\text { (A) }\end{array}$ & $\begin{array}{l}\text { Uterine vein } \\
\text { (V) }\end{array}$ & $\begin{array}{c}\text { Fetal } \\
\text { femoral artery } \\
\text { (a) }\end{array}$ & $\begin{array}{l}\text { Umbilical vein } \\
\text { (v) }\end{array}$ \\
\hline \multicolumn{5}{|c|}{ Glucose (mM) } \\
\hline Period 2 & $4.12 \pm 0.06^{* *}$ & $3.88 \pm 0.07^{* *}$ & $1.25 \pm 0.06 \S$ & $1.47 \pm 0.06^{* *}$ \\
\hline \multicolumn{5}{|c|}{ Lactate (mM) } \\
\hline Period 1 & $0.68 \pm 0.03$ & $0.72 \pm 0.03$ & $1.78 \pm 0.13$ & $1.90 \pm 0.14$ \\
\hline Period 1 & $93.3 \pm 0.8$ & $73.5 \pm 1.3$ & $51.9 \pm 2.0$ & $80.9 \pm 1.7$ \\
\hline Period 2 & $93.5 \pm 0.7$ & $73.5 \pm 1.3$ & $44.4 \pm 2.3^{* *}$ & $74.7 \pm 2.1^{* *}$ \\
\hline \multicolumn{5}{|c|}{ Hemoglobin (mM) } \\
\hline Period 1 & $6.06 \pm 0.17$ & $6.06 \pm 0.16$ & $5.96 \pm 0.19$ & $5.92 \pm 0.20$ \\
\hline Period 2 & $5.89 \pm 0.16^{* *}$ & $5.91 \pm 0.16^{*}$ & $5.73 \pm 0.18^{* *}$ & $5.72 \pm 0.18^{* *}$ \\
\hline \multicolumn{5}{|c|}{ Hematocrit (\%) } \\
\hline Period 2 & $5.40 \pm 0.14^{* *}$ & $4.22 \pm 0.10 \S$ & $2.46 \pm 0.14^{* *}$ & $4.10 \pm 0.14 * *$ \\
\hline
\end{tabular}

Values expressed as mean \pm SEM. $p$ value determined by two-tailed, paired $t$ test; differences between period 1 and period $2 . \S p<0.05, * p<0.01, * * p<$ 0.005 .

Table 4. Glucose, lactate, and oxygen uptakes during study period 1 (normal maternal plasma arginine concentration) and study period 2 (elevated maternal plasma arginine concentration)

\begin{tabular}{|c|c|c|}
\hline & Period 1 & Period 2 \\
\hline \multicolumn{3}{|l|}{ Glucose uptake } \\
\hline Uterine $(\mu \mathrm{mol} / \mathrm{min})$ & $369 \pm 24$ & $363 \pm 19$ \\
\hline Uterine $/ \mathrm{kg}$ fetus $\left(\mu \mathrm{mol} \cdot \mathrm{kg}^{-1} \cdot \mathrm{min}^{-1}\right)$ & $129 \pm 8$ & $126 \pm 6.2$ \\
\hline Umbilical $/ \mathrm{kg}$ fetus $\left(\mu \mathrm{mol} \cdot \mathrm{kg}^{-1} \cdot \mathrm{min}^{-1}\right)$ & $35 \pm 2$ & $40 \pm 2$ \\
\hline Uteroplacental ( $\mu \mathrm{mol} / \mathrm{min})$ & $270 \pm 23$ & $250 \pm 18$ \\
\hline Uteroplacental $/ \mathrm{kg}$ placenta $\left(\mu \mathrm{mol} \cdot \mathrm{kg}^{-1} \cdot \min ^{-1}\right)$ & $795 \pm 78$ & $765 \pm 101$ \\
\hline Uterine $/ \mathrm{kg}$ fetus $\left(\mu \mathrm{mol} \cdot \mathrm{kg}^{-1} \cdot \mathrm{min}^{-1}\right)$ & $-15.7 \pm 3.9$ & $-20.1 \pm 3.3$ \\
\hline Umbilical ( $\mu \mathrm{mol} / \mathrm{min})$ & $70.9 \pm 7.0$ & $70.6 \pm 8.5$ \\
\hline Umbilical $/ \mathrm{kg}$ fetus $\left(\mu \mathrm{mol} \cdot \mathrm{kg}^{-1} \cdot \mathrm{min}^{-1}\right)$ & $25.0 \pm 2.2$ & $25.1 \pm 2.6$ \\
\hline Uteroplacental $(\mu \mathrm{mol} / \mathrm{min})$ & $-117.8 \pm 16.5$ & $-128.0 \pm 14.4$ \\
\hline Uteroplacental $/ \mathrm{kg}$ placenta $\left(\mu \mathrm{mol} \cdot \mathrm{kg}^{-1} \cdot \min ^{-1}\right)$ & $-331.4 \pm 59.7$ & $-393.2 \pm 61.2$ \\
\hline \multicolumn{3}{|l|}{ Oxygen uptake } \\
\hline Uteroplacental $(\mu \mathrm{mol} / \mathrm{min})$ & $913 \pm 104$ & $962 \pm 121$ \\
\hline Uteroplacental $/ \mathrm{kg}$ placenta $\left(\mu \mathrm{mol} \cdot \mathrm{kg}^{-1} \cdot \min ^{-1}\right)$ & $2715 \pm 373$ & $3099 \pm 289$ \\
\hline
\end{tabular}

No significant differences in uptakes between periods 1 and 2 as determined by paired, two-tailed $t$ test.

* A negative lactate uptake implies a net lactate production.

nificant effects on maternal, placental, and fetal arginine flux and metabolism.

Although previous studies in pregnant sheep have measured the effect of maternal arginine administration on fetal arginine concentrations (5), umbilical (fetal) and uteroplacental uptake rates of arginine have not been evaluated after maternal arginine supplementation or in relation to changes in maternal plasma arginine concentration. Uterine arginine uptake rate represents the supply of arginine to both uteroplacental unit and fetus from the maternal plasma, whereas umbilical arginine net uptake rate represents the supply of arginine to the fetus from the placenta. The difference between uterine and umbilical net arginine uptake rates defines the net rate of arginine metabolism by the uteroplacental unit. More than $75 \%$ of uteroplacental metabolism is accounted for by the placenta $(17,19)$. In the present study, net uterine arginine uptake exceeded net umbilical (fetal) arginine uptake by $46 \%$ in the basal period; thus, the uterine uptake of arginine was partitioned about one third into net uteroplacental consumption and about two thirds into transfer to the fetus. At increased maternal arginine concentrations, net uterine arginine uptake exceeded net umbilical (fetal) arginine uptake by 2.8 -fold, ac- 



Figure 2. Mean plasma arginine concentrations during normal (period 1) and elevated (period 2) maternal arginine concentration. Comparison of values in period 2 vs period $1,{ }^{*} p<0.05$ and ${ }^{* *} p<0.005$ by two-tailed, paired $t$ test. (MPE, mol percent enrichment.)

counted for by a 4.2-fold greater increase in uteroplacental consumption of arginine than transfer to the fetus.

This increase in the ratio of uteroplacental-to-umbilical net arginine uptake rate at increased maternal plasma arginine concentration might represent preferential uteroplacental arginine metabolism relative to fetal arginine metabolism at greater than normal rates of arginine supply and plasma concentrations, but also might indicate relatively limited placental-tofetal arginine transport capacity compared with uterine or uteroplacental arginine uptake; i.e. placental-to-fetal transport rate could be close to maximal and thus placental-to-fetal transport capacity could be close to saturated at normal maternal and fetal plasma arginine concentrations although uterine or uteroplacental uptake capacity remains unsaturated. This could occur by a more limited concentration of transporters per membrane surface area on the fetal side of the placenta; i.e. placental-to-fetal $V_{\max }$ is lower than maternal-to-placental $V_{\max }$. In this regard, it also is important to note that the surface area of the maternal-facing microvillous membrane is much greater than that of the basal membrane because of its brush border. This property alone could confer marked advantage to placental arginine uptake from the maternal plasma but relatively limited transport capacity to the fetus.
Arginine is transported across membranes by the loweraffinity, higher-capacity cationic transporter system $\mathrm{y}^{+}$(which does not transport neutral amino acids such as glutamine and leucine), and the higher-affinity, lower-capacity cationic amino acid transport system $\mathrm{y}^{+} \mathrm{L}$ (which does transport and therefore competes with neutral amino acids such as L-glutamine and L-leucine). System $\mathrm{y}^{+}$and system $\mathrm{y}^{+} \mathrm{L}$ have been found on the maternal-facing microvillous membrane of first-trimester and term human placentas $(20,21)$ whereas only system $y^{+} \mathrm{L}$ is found on the fetal-facing basal membrane in term placentas (20). In the present study the relatively lower placental-to-fetal arginine transport rates compared with the relatively higher uterine-to-uteroplacental arginine uptake rates at higher maternal arginine concentrations also might indicate that the transporters available to transport arginine from the trophoblast cells of the placenta to the fetal plasma are predominantly of the higher-affinity, lower capacity type, i.e. of the $\mathrm{y}^{+} \mathrm{L}$ transport system more than the $\mathrm{y}^{+}$system. System $\mathrm{y}^{+} \mathrm{L}$ also transports lysine, which interestingly appears to share the same characteristic in the sheep as does arginine of low transport under basal concentrations and marked increase in uteroplacental net uptake (consumption) relative to placental-to-fetal transport at higher maternal concentrations (22). Which of these transporters are present and on which membranes in the sheep are not yet known; neither is it known how they would regulate the kinetics of arginine transport that we have observed. However, a predominance of lower-affinity, highercapacity transporters on the maternal-facing microvillous membrane and higher-affinity, lower capacity transporters on the basal membrane might contribute to the net transport kinetics observed in the present study in which an increased supply of arginine to the uterus was partitioned more into uteroplacental net uptake than to placental-to-fetal transport. This speculation deserves further study.

An interesting observation in this study was that there was a small but significant increase in fetal plasma arginine enrichment $(+32 \%)$, owing to a greater increase in fetal tracer than tracee concentration, and consistent with a relatively greater increase in net fetal arginine tracer uptake rate $(+74 \%)$ than net tracee arginine uptake rate $(+56 \%)$. This could occur by several possible mechanisms. First, the increase in tracee arginine transfer might have been limited by mass action, a possibility indicated by the smaller increase in disposal rate $(+26 \%)$ than net uptake rate of arginine $(+55 \%)$, indicating that the increased transfer of tracee arginine did two things: 1 ) increased fetal plasma arginine concentration; 2) decreased fetal arginine production rate. The end result would have been a lesser increase in fetal plasma arginine concentration and thus plasma arginine pool size than from arginine uptake alone. These kinetics would not have applied to the tracer, because there is no fetal tracer arginine production. Second, as we have seen with glucose and glucose tracer, it is very likely under these circumstances that tracer disposal was a balance between increased utilization owing to increased uptake or concentration and decreased utilization owing to competition with the increased tracee arginine concentration; the latter may have predominated. Third, the relatively greater fetal uptake of tracer than tracee could have been the result of an increased 
Table 5. Arginine uptakes, and disposal rates and clearance during study period 1 (normal maternal plasma arginine concentration) and study period 2 (elevated maternal plasma arginine concentration)

\begin{tabular}{|c|c|c|}
\hline & Period 1 & Period 2 \\
\hline \multicolumn{3}{|l|}{ Arginine uptake } \\
\hline Uterine $(\mu \mathrm{mol} / \mathrm{min})$ & $13.84 \pm 1.04$ & $41.25 \pm 7.70^{* *}$ \\
\hline Umbilical $(\mu \mathrm{mol} / \mathrm{min})$ & $9.51 \pm 1.61$ & $14.80 \pm 2.81 * *$ \\
\hline Uteroplacental $(\mu \mathrm{mol} / \mathrm{min})$ & $4.33 \pm 1.38$ & $26.45 \pm 6.74 \S$ \\
\hline Uteroplacental $/ \mathrm{kg}$ placenta $\left(\mu \mathrm{mol} \cdot \mathrm{kg}^{-1} \cdot \mathrm{min}^{-1}\right)$ & $17.80 \pm 6.15$ & $89.24 \pm 20.26^{*}$ \\
\hline Uteroplacental clearance $/ \mathrm{kg}$ placenta $\left(\mathrm{mL} \cdot \mathrm{kg}^{-1} \cdot \mathrm{min}^{-1}\right)$ & $86.0 \pm 29.7$ & $53.5 \pm 13.6$ \\
\hline Maternal DR $/ \mathrm{kg}$ maternal weight $\left(\mu \mathrm{mol} \cdot \mathrm{kg}^{-1} \cdot \mathrm{min}^{-1}\right)$ & $3.52 \pm 0.31$ & $5.30 \pm 0.35^{* *}$ \\
\hline Fetal DR $(\mu \mathrm{mol} / \mathrm{min})$ & $22.4 \pm 2.5$ & $28.0 \pm 3.7 \S$ \\
\hline Fetal DR $/ \mathrm{kg}$ fetus $\left(\mu \mathrm{mol} \cdot \mathrm{kg}^{-1} \cdot \mathrm{min}^{-1}\right)$ & $7.92 \pm 0.75$ & $9.94 \pm 1.13 \S$ \\
\hline Fetal OxR $(\mu \mathrm{mol} / \mathrm{min})$ & $3.61 \pm 0.64$ & $5.11 \pm 0.9 \S$ \\
\hline Fetal OxR/kg fetus $\left(\mu \mathrm{mol} \cdot \mathrm{kg}^{-1} \cdot \mathrm{min}^{-1}\right)$ & $1.31 \pm 0.24$ & $1.84 \pm 0.36 \S$ \\
\hline$\%$ fetal arginine DR directed to fetal arginine OxR & $15.9 \pm 2.5$ & $17.5 \pm 2.0$ \\
\hline Uteroplacental clearance $/ \mathrm{kg}$ placenta $\left(\mathrm{mL} \cdot \mathrm{kg}^{-1} \cdot \mathrm{min}^{-1}\right)$ & $86.0 \pm 29.7$ & $53.5 \pm 13.6$ \\
\hline
\end{tabular}

Values expressed as mean \pm SEM. $p$ value determined by two-tailed, paired $t$ test; differences between period 1 and period 2 . $\$ p<0.01, * p<0.01, * * p<$ 0.005 .

exchange capacity of the tracer with the increased fetal arginine pool, whereas the arginine pool in the uteroplacental unit might not have increased as much because of increased uteroplacental utilization. Finally, it also is possible that the fetal tracer concentration in period 1 had not yet reached steadystate, in which case its concentration in the fetus could have increased from period 1 to period 2 independently of tracee arginine. Which of these several factors led to the small increase in fetal plasma arginine enrichment in period 2 cannot be determined from the data in this study. Confirmation of these observations will require a more complete experimental approach with bidirectional kinetic analysis of tracers and tracee infused into the mother and the fetus at different maternal and fetal arginine concentrations, similar to our previously published kinetic analysis of placental glucose transfer and metabolism (23).

Mechanisms that regulate arginine uptake, metabolism, and transport by the placenta have not been studied and remain ambiguous. Three aspects of this lack of understanding are important to consider regarding results of the present study. First, the metabolic fate of the remarkably increased uteroplacental utilization and fetal arginine concentration is unknown. In a study of whole-body arginine kinetics in healthy adult males at both normal and 10 times normal arginine dietary intakes, both plasma arginine and ornithine fluxes, as well as conversion of arginine to ornithine, were significantly increased, whereas there was no apparent increase in nitric oxide from arginine (24). Plasma insulin concentrations were significantly increased in the high-arginine intake group. There was an overall decrease in urea production and excretion in the arginine-supplemented group, and it was hypothesized that this could be secondary to the overall anabolic effect of increased insulin. In the present study, amino acid profiles performed in a subset of animals showed increased maternal and fetal plasma ornithine concentration, but not citrulline concentra- tion, in the arginine-supplemented group. This could occur by catabolism of arginine to ornithine and urea in the placenta via arginase action. Arginase reaches maximal concentrations in the sheep placenta in late gestation (25). Whether its concentration or activity could be augmented by increased arginine uptake by the placenta is not known. Similar observations have been made for lysine in the sheep, in which an increase in maternal lysine concentration did not demonstrate increased transport to the fetus, indicating increased catabolism of lysine in the placenta (22). This increased catabolism is similar to that reported by substrate activation of catabolic enzyme genes by the intestine in milk protein-fed piglets (26) and in the perfused rat liver (27). An important phenomenon in placenta, intestine, and liver, therefore, may be the capacity for amino acid regulation of gene activation that induces catabolism of the amino acid to limit its concentration or to provide alternative end products of catabolism (e.g. ornithine in the case of arginine). Ornithine cannot be converted to urea in the placenta because ornithine transcarbamylase is absent, but this enzyme is present in fetal liver where it could use the ornithine produced in the placenta to produce urea.

Second, arginine may play a role in fetal growth. One potential mechanism for this effect is via arginine stimulation of fetal insulin release. Insulin is an essential hormone for fetal growth (28), and the pancreas in the fetal sheep releases insulin in response to a number of nonglucose secretagogues, including arginine $(3,4)$. Several studies in fetal sheep have shown that fetal arginine infusion increases fetal plasma insulin concentration, a phenomenon that increases with gestational age $(3,29)$. Whether this capacity has physiologic significance, however, is uncertain. For example, Gresores et al. (5) examined the acute effect of five different fetal arginine bolus infusions (increasing fetal arginine 1.5- to 10 -fold) on fetal arginine concentration at normal and increased glucose concentrations (approximately $50 \%$ and $100 \%$ above basal glu- 
cose). At normoglycemia, a change in fetal arginine concentration did not significantly affect fetal insulin secretion until fetal arginine was in the high physiologic range (i.e. $>100 \%$ above the mean value of normal concentrations), indicating that in fetal sheep a physiologic increase in fetal arginine does not act as a significant insulin secretagogue. In the present study, the increase in fetal insulin produced by a 3 -fold increase in maternal arginine was not sufficient to alter either maternal or fetal glucose concentration or net fetal glucose uptake rate. In general, a measurable increase in fetal glucose utilization is not seen until there is an increase in fetal insulin concentration of 2- to 3-fold (i.e. an increase of 20-30 $\mu \mathrm{U} / \mathrm{mL}$ above baseline) (30). In contrast to this relatively blunted relationship among change in fetal arginine concentration, insulin secretion, and altered glucose metabolism, even small increases in insulin might produce an anabolic effect. For example, we have measured a direct and quite steep relationship between insulin concentrations and fetal utilization rates of most amino acids over the lower physiologic range of plasma insulin concentrations in late-gestation fetal sheep (31). Thus, a change in maternal arginine concentration sufficiently large to increase fetal arginine and insulin concentrations might have a definite anabolic effect on amino acid utilization in the fetus. Studies are underway to test this hypothesis.

Third, glucose appears capable of increasing the $V_{\max }$ for arginine uptake by choriocarcinoma-derived BeWo cells, and this can be augmented by insulin (32). This phenomenon has not been tested specifically in vivo. In the present study, however, glucose concentrations did not change, and the increases in maternal and fetal insulin concentrations were modest relative to the pharmacologic changes in insulin used in the BeWo cell studies. Furthermore, our previous studies of maternal and fetal hyperglycemia and hyperinsulinemia showed no effect of these conditions on arginine uptake, metabolism, or transport by the ovine placenta. Thus, it is unlikely in the present studies that those effects of glucose and insulin observed in BeWo cells were operative.

In summary, maternal i.v. arginine infusion sufficient to increase the maternal plasma arginine concentration 3-fold results in increased net uterine, uteroplacental, and umbilical (fetal) arginine uptake rate. The majority of the increased uterine arginine uptake rate, however, is primarily used by the uteroplacental unit. Nevertheless, this increase in maternal arginine concentration does produce significant increases in the net transport of arginine from the placenta to the fetus, net fetal arginine uptake rate, and fetal plasma arginine and insulin concentrations. We speculate that the increase in fetal insulin concentrations secondary to maternal arginine supplementation might support a fetal anabolic effect. This effect should be particularly important to study in pregnancies carrying a growth-restricted fetus in which fetal arginine and insulin concentrations are low.

\section{REFERENCES}

1. Rogers QR, Chen DM, Harper AE 1970 The importance of dispensable amino acids for maximal growth in the rat. Proc Soc Exp Biol Med 134:517-522

2. Wu G, Meininger CJ, Knabe DA, Bazer FW, Rhoads JM 2000 Arginine nutrition in development, health and disease. Curr Opin Clin Nutr Metab Care 3:59-66

3. Fowden AL 1980 Effects of arginine and glucose on the release of insulin in the sheep fetus. J Endocrinol 85:121-129

4. Fowden AL 1980 Effects of adrenaline and amino acids on the release of insulin in the sheep fetus. J Endocrinol 87:113-121

5. Gresores A, Anderson S, Hood D, Zerbe GO, Hay Jr WW 1997 Separate and joint effects of arginine and glucose on ovine fetal insulin secretion. Am J Physiol 272:E68-E73

6. Carver TD, Anderson SM, Aldoretta PA, Esler AL, Hay Jr WW 1995 Glucose suppression of insulin secretion in chronically hyperglycemic fetal sheep. Pediatr Res 38:754-762

7. Milner RDG, Ashworth MA, Barson AJ 1972 Insulin release from human foetal pancreas in response to glucose, leucine and arginine. J Endocrinol 52:497-505

8. King KG, Butt J, Raivio K, Raiha N, Roux J, Teramo K, Yamaguchi K, Schwartz R 1971 Human maternal and fetal insulin response to arginine. N Engl J Med 285:607612

9. Reitano G, Grasso S, Distefano G, Messina A 1971 The serum insulin and growth hormone response to arginine and to arginine with glucose in the premature infant. $\mathrm{J}$ Clin Endocrinol Metab 33:924-928

10. Grasso S, Messina A, Distefano G, Vigo R, Reitano G 1973 Insulin secretion in the premature infant: response to glucose and amino acids. Diabetes 22:349-353

11. Morgan DM 1999 Polyamines: an overview. Mol Biotechnol 11:229-250

12. Wu G, Morris Jr SM 1998 Arginine metabolism: nitric oxide and beyond. Biochem J $15: 1-17$

13. Beaumier L, Castillo L, Yu YM, Ajami AM, Young VR 1996 Arginine: new and exciting developments for an "old" amino acid. Biomed Environ Sci 9:296-315

14. Fisker S, Nielsen S, Ebdrup L, Bech JN, Christiansen JS, Pedersen EB, Jorgensen JO 1999 The role of nitric oxide in L-arginine-stimulated growth hormone release. J Endocrinol Invest 22:89-93

15. Milner JA, Wakeling AE, Visek WJ 1974 Effect of arginine deficiency on growth and intermediary metabolism in rats. J Nutr 104:1681-1689

16. Hoogenraad N, Totino N, Elmer H, Wraight C, Alewood P, Johns RB 1985 Inhibition of intestinal citrulline synthesis causes severe growth retardation in rats. Am J Physiol 249:G792-G799

17. Meschia G, Battaglia FC, Hay Jr WW, Sparks JW 1980 Utilization of substrates by the ovine placenta in vivo. Fed Proc 39:245-249

18. Chung M, Teng C, Timmerman M, Meschia G, Battaglia FC 1998 Production and utilization of amino acids by ovine placenta in vivo. Am J Physiol 274:E13-E22

19. Makowski EL, Meschia G, Droegemueller W, Battaglia FC 1968 Distribution of uterine blood flow in the pregnant sheep. Am J Obstet Gynecol 101:409-412

20. Ayuk P T-Y, Sibley CP, Donnai P, D'Souza S, Glazier JD 2000 Development and polarization of cationic amino acid transporters and regulators in the human placenta. Am J Physiol 278:C1162-C1171

21. Furesz TC, Moe AJ, Smith CH 1991 Two cationic amino acid transport systems in human placental basal plasma membranes. Am J Physiol 261C246-C252

22. Wilkes P, Zhu Y, Teng C, Meschia G, Wilkening R, Fennessey P, Battaglia F 2001 The effect of an elevated maternal lysine concentration on lysine transport and catabolism in the ovine model. Am J Obstet Gynecol 184:S91(abstr)

23. Hay Jr WW, Molina RD, DiGiacomo JE, Meschia G 1990 Model of placental glucose consumption and glucose transfer. Am J Physiol 258:R569-R577

24. Beaumier L, Castillo L, Ajami AM, Young VR 1995 Urea cycle intermediate kinetics and nitrate excretion at normal and "therapeutic" intakes of arginine in humans. Am J Physiol 269:E884-E896

25. Edwards EM, Rattenbury JM, Varnam GCE, Dhand UK, Jeacock MK, Shepherd DAL 1977 Enzyme activities in the sheep placenta during the last three months of pregnancy. Biochim Phiophys Acta 497:133-143

26. Stoll B, Henry J, Reeds PJ, Yu H, Jahoor F, Burrin DG 1998 Catabolism dominates the first-pass intestinal metabolism of dietary essential amino acids in milk protein-fed piglets. J Nutr 128:606-614

27. O'Sullivan D, Brosnan JT, Brosnan ME 1996 Catabolism of arginine and ornithine in perfused rate liver; localisation and regulation. Biochim Soc Trans 24:488S

28. Fowden AL 1992 The role of insulin in fetal growth. Early Hum Dev 29:177-181

29. Aldoretta PW, Carver TD, Hay Jr WW 1998 Maturation of glucose-stimulated insulin secretion in fetal sheep. Biol Neonate 73:375-386

30. Hay Jr W, Meznarich H, DiGiacomo J, Hirst K, Zerbe G 1988 Effects of insulin and glucose concentration on glucose utilization in fetal sheep. Pediatr Res 23:381-387

31. Thureen PJ, Scheer B, Anderson SM, Tooze JA, Young DA, Hay Jr WW 2000 Effect of hyperinsulinemia on amino acid utilization in the ovine fetus. Am J Physiol 279:E1294-E1302

32. Eaton BM, Sooranna SR 1998 In vitro modulation of L-arginine transport in trophoblast cells by glucose. Eur J Clin Invest 28:1006-1010 